\title{
STUDY OF CORRELATION BETWEEN BMI AND PEFR RATE IN RAYALASEEMA POPULATION
}

\section{G. Reen Prasoona, S Sarah Nightigale *.}

Assistant Professor, Physiology Kurnool Medical college, Kurnool, Rayalaseema, Andhra Pradesh, India.

\section{ABSTRACT}

Introduction: Obesity, waist-hip ratio, rather than Body Mass Index (BMI) explains large part of the variance in pulmonary gas exchange. Hence, present study will be taken up to study the correlation between BMR, and Peak Expiratory flow rate (PEFR) in healthy underweight, normal weight, and obese adults.

Materials and Methods: The present cross section study conducted in the department of Physiology, Kurnool medical college, Kurnool, with randomly selected 100 health voluntaries from both the sexes of the age group 20-40 yrs. The height and weight were taken to calculated BMI and PEFR was recorded.

Results: The mean PEFR values were significantly lower in obese group when compared to normal weight. BMI was significantly and negatively correlated with PEFR in both males and females.

Conclusion: The isolated effects of obesity unassociated with other diseases must be identified and the analysis of those effects should be stratified so that obesity related dysfunction may be evaluated in detail.

KEY WORDS: Body Mass Index, Obesity, and, Peak Expiratory Flow Rate.

Address for correspondence: S Sarah Nightigale, Assistant Professor, Physiology Kurnool Medical college, Kurnool, Rayalaseema, Andhra Pradesh, India. E-Mail: reenagollapalli@gmail.com

\begin{tabular}{|l|l|}
\hline \multicolumn{3}{|c|}{ Online Access and Article Informtaion } \\
\hline Quick Response code & \multicolumn{1}{|c|}{ International Journal of Integrative Medical Sciences } \\
& \multicolumn{1}{|c|}{ ISSN (P): 2394-6318. ISSN (E): 2394 - 4137} \\
www.imedsciences.com
\end{tabular}

\section{INTRODUCTION}

Global warming, climate change and extremes of temperatures are causing the environmental associated harmful toxic air pollution over the last four decades [1]. More specifically in the Kurnool districts drastic climatic changes and factories the effect of respirable suspended particulate matters and other noxious environmental hazards such as nitrogen dioxide, Sulphur dioxide, and carbon monoxide on respiratory performance is also poorly understood [2]. The available data on the suspended particulate matters in air of Kurnool. Metabolic Rate (BMR) is one of the major components constituting $60-70 \%$ of total daily energy expenditure. The rates of energy expenditure show strong familial aggregation and low metabolic rate for a given body size and body composition is a risk factor for body weight gain [3]. BMR has frequently been the main focus of attention in the studies on the developments and treatment of obesity. Generally, BMR depends on body composition as expressed by Fat Free Mass (FFM) and fat mass and depends on gender, age, physical activity and nutritional status [4]. 24 hour energy expenditure was higher in male individuals than female individuals after adjusting for differences in fat-free mass, fat mass and age. Male individuals tend to have higher BMR after adjusting for differences in body composition, age and activity [3], and There exists an inverse relationship between age and 
BMR. The age-related decline in BMR was due to a reduction in FFM. Finally, anthropometric predictors of BMR were as accurate as body composition [4].

Many studies have demonstrated associations between ventilatory dysfunction and excess weight or body fat distribution. A central pattern of fat distribution is negatively associated with respiratory function in elderly persons [5]. Obesity reduces thoracic wall compliance by restricting diaphragm movement and thoracic cage expansion. It has also been suggested that waist-hip ratio, rather than Body Mass Index (BMI) explains large part of the variance in pulmonary gas exchange [6]. Hence, present study will be taken up to study the correlation between $B M R$, and peak Expiratory flow rate (PEFR) in healthy underweight, normal weight, and obese adults.

\section{MATERIALS AND METHODS}

The present cross section study conducted in the department of Physiology, Kurnool medical college, Kurnool, with randomly selected 100 health voluntaries from both the sexes of the age group 20-40 yrs, physically and mentally fit, non-smokers, no acute respiratory illness or no medical complication were included in the study. Family history and personal history along with the resting pulse rate and blood pressure was recorded. Height $(\mathrm{cm})$ and weight $(\mathrm{kg})$ of the subjects will be recorded and BMI calculated as per Quetelet's index [7].

$$
\mathrm{BMI}=\frac{\text { Weight }(\mathrm{kg})}{\text { Height }\left(\mathrm{m}^{2}\right)}
$$

Subjects were classified into 3 groups as per WHO recommendation depending upon $\mathrm{BMI}$ as follows:

Under weight : $<18.5\left(\mathrm{~kg} / \mathrm{m}^{2}\right)$

Normal weight : $\mathrm{BMI}=18.5-24.99\left(\mathrm{~kg} / \mathrm{m}^{2}\right)$

Over weight : $\mathrm{BMI}=25.0-29.99\left(\mathrm{~kg} / \mathrm{m}^{2}\right)$

Obese : $\mathrm{BMI}>30\left(\mathrm{~kg} / \mathrm{m}^{2}\right)$

Peak Expiratory Flow Rate (PEFR): The peak expiratory flow rate was determined as previously described [8]. Using Wright's peak flow meter. The subjects were asked to stand in an upright position with the peak flow meter held horizontally in front of their mouth and allowed to take a deep breath in, and closed the lips firmly around the mouthpiece, making sure that no air leaks around the lips. The subject was asked to breathe out as hard and as fast as possible and the around the lips. The subject was asked to breathe out as hard and as fast as possible and the number indicated by the cursor was noted and the sequence was repeated twice more, thus obtaining three readings. The highest or best reading of all three measurements was taken as the peak flow rate.

Statistical analysis was done using SPSS version 11.0 and Microsoft office excel 2007.Values were analyzed based on weight, BMI, and PEFR. Correlation analysis will be performed to assess the relationship between different parameters by Pearson's correlation coefficient.

\section{RESULTS}

Randomly selected 100 health voluntaries from both the sexes 49 males (49\%) and 51 females (51\%) were included in the study, most common age group is $20-40$ years. Subjects will be classified into 3 groups as per WHO recommendation depending upon BMI. 9 Under weight (male: 2, Female:7), 28 Normal weight (male: 16, Female:12), 45 Over weight (male: 24, Female:21) and 18 Obese (male:7, Female:11).

Table 1: Comparison of Physical parameters and PEFR in between the males and females.

\begin{tabular}{|c|c|c|c|}
\hline Variables & Male & Female & P-value \\
\hline Age (yrs) & $30.122 \pm 5.50$ & $29.117 \pm 5.46$ & $>0.05$ \\
\hline Weight (Kg) & $73.612 \pm 12.44$ & $62.774 \pm 13.15$ & $<0.001$ \\
\hline Height (Mts) & $1.672 \pm 0.08$ & $1.556 \pm 0.05$ & $<0.001$ \\
\hline BMI (Kg/m2) & $26.254 \pm 4.37$ & $26.059 \pm 5.78$ & $>0.05$ \\
\hline PEFR (lit/min) & $479.183 \pm 50.40$ & $309.80 \pm 81.42$ & $<0.001$ \\
\hline
\end{tabular}

There is statistically deference was found in the PEFR (lit/min) between males and female.

\section{DISCUSSION}

The magnitude of the upswing in overweight and obesity prevalence has been truly astonishing. It has now become an important health problem in developing countries particularly in India. The consequence of industrialization and urbanization which lead to decrease in physical 
G. Reen Prasoona, S Sarah Nightigale. STUDY OF CORRELATION BETWEEN BMI AND PEFR RATE IN RAYALASEEMA POPULATION.

Table 2: Comparison of Physical parameters and PEFR in between the groups.

\begin{tabular}{|c|c|c|c|c|c|c|}
\hline \multicolumn{2}{|c|}{ Variables } & Under Weight & Normal Weight & Over Weight & Obese & p-value \\
\hline \multirow{2}{*}{ Age (yrs) } & Male & $22.5 \pm 0.70$ & $28.56 \pm 5.64$ & $30.87 \pm 4.62$ & $33.28 \pm 6.42$ & $<0.005$ \\
\cline { 2 - 8 } & Female & $23.285 \pm 3.03$ & $27 \pm 3.35$ & $29.476 \pm 5.24$ & $35.454 \pm 3.95$ & $<0.001$ \\
\hline \multirow{2}{*}{ Weight (Kg) } & Male & $47.5 \pm 3.53$ & $66 \pm 7.76$ & $76.12 \pm 7.29$ & $89.85 \pm 12.95$ & $<0.001$ \\
\cline { 2 - 8 } & Female & $42.357 \pm 5.022$ & $53.75 \pm 5.50$ & $66.761 \pm 4.96$ & $78 \pm 9.43$ & $<0.001$ \\
\hline \multirow{2}{*}{ Height (Mts) } & Male & $1.675 \pm 0.003$ & $1.679 \pm 0.07$ & $1.683 \pm 0.07$ & $1.621 \pm 0.11$ & $>0.05$ \\
\cline { 2 - 8 } & Female & $1.574 \pm 0.072$ & $1.578 \pm 0.059$ & $1.554 \pm 0.055$ & $1.522 \pm 0.041$ & $>0.05$ \\
\hline \multirow{2}{*}{ BMI (Kg/m ${ }^{2}$ ) } & Male & $16.975 \pm 1.98$ & $23.010 \pm 1.36$ & $26.885 \pm 1.35$ & $34.157 \pm 3.10$ & $<0.001$ \\
\cline { 2 - 8 } & Female & $17.052 \pm 0.879$ & $21.648 \pm 2.683$ & $27.646 \pm 1.378$ & $33.573 \pm 3.043$ & $<0.001$ \\
\hline \multirow{2}{*}{ PEFR (lit/min) } & Male & $420 \pm 42.42$ & $500.62 \pm 39.40$ & $491.66 \pm 33.05$ & $404.28 \pm 48.94$ & $<0.001$ \\
\cline { 2 - 8 } & Female & $297.14 \pm 91.78$ & $401.66 \pm 28.23$ & $309.52 \pm 59.28$ & $218.18 \pm 26.76$ & $<0.001$ \\
\hline
\end{tabular}

The difference of the mean value of PEFR between Underweight, normal weight, overweight and obese were found statistically significant in the males $(<0.001)$ and females $(<0.001)$.

Table 3: Comparison of PEFR between underweight, normal weight, over weight, Obese subjects.

\begin{tabular}{|c|c|c|c|c|}
\hline \multicolumn{3}{|c|}{ Variables } & Male & Female \\
\hline \multirow{12}{*}{$\begin{array}{c}\text { PEFR } \\
\text { (lit/min) }\end{array}$} & \multirow{3}{*}{ Under Weight } & Normal weight & $<0.05$ & $<0.01$ \\
\hline & & over weight & $<0.01$ & $>0.05$ \\
\hline & & obese & $>0.05$ & $<0.05$ \\
\hline & \multirow{3}{*}{ Normal weight } & Under Weight & $<0.05$ & $<0.01$ \\
\hline & & over weight & $>0.05$ & $<0.001$ \\
\hline & & obese & $<0.001$ & $<0.001$ \\
\hline & \multirow{3}{*}{ over weight } & Under Weight & $<0.01$ & $>0.05$ \\
\hline & & Normal weight & $>0.05$ & $<0.001$ \\
\hline & & obese & $<0.001$ & $<0.001$ \\
\hline & \multirow{3}{*}{ obese } & Under Weight & $>0.05$ & $<0.05$ \\
\hline & & Normal weight & $<0.001$ & $<0.001$ \\
\hline & & over weight & $<0.001$ & $<0.001$ \\
\hline
\end{tabular}

PEFR was statistically significantly negatively correlated with $\mathrm{BMI}$ in the males $(r=-0.43477$; $p=<0.01)$ and Females $(r=-0.53302 ; p=<0.001)$

Table 4: Correlation of PEFR and Physical parameters of the male and female subjects.

\begin{tabular}{|c|c|c|c|}
\hline \multicolumn{2}{|c|}{ Variables } & $\begin{array}{c}\text { Correlation Coefficient } \\
\text { (r value) }\end{array}$ & p-value \\
\hline \multirow{2}{*}{ Age (yrs) } & Male & -0.14815 & $>0.05$ \\
\cline { 2 - 4 } & Female & -0.31502 & $<0.05$ \\
\hline \multirow{2}{*}{ Height (Mts) } & Male & 0.444737 & $<0.01$ \\
\cline { 2 - 4 } & Female & 0.496953 & $<0.001$ \\
\hline \multirow{2}{*}{ Weight (Kg) } & Male & -0.14098 & $>0.05$ \\
\cline { 2 - 4 } & Female & -0.39757 & $<0.01$ \\
\hline \multirow{2}{*}{ BMI (Kg/m2) } & Male & -0.43477 & $<0.01$ \\
\cline { 2 - 4 } & Female & -0.53302 & $<0.001$ \\
\hline
\end{tabular}

activity together with substantial dietary changes and over all pattern of life style promote weight gain [9]. Being overweight or obese increases the risk of many diseases and health conditions including respiratory problem [9].

The present study was planned to assess the correlation between body mass index and PEFR in adult of both sexes between the age group of $20-40$ year. It was observed that mean PEFR value was significantly higher in male $(479 \pm 50.4)$ subjects in comparison to female (309 \pm 81.42$)$ subjects. This may be due to significant higher value of mean standing height along with muscular force in male subjects $(p=<0.001)$ as compared to female. Similar findings were observed in the studies done by Ebomoyi et.al. [10], Kusal. K. Das et.al.[11], Dhungel K.U. et. al. [12] although the age of the study was lower in these studies when compared to the present study. There was significant difference $(p=<0.001)$ of mean values of height and weight between males and females. Similar findings were observed in the study done by Kusal. K. Das et.al.[11]. In the present study mean value of weight is $62 \pm 13$ and height is $1.55 \pm 0.55$ in female and in males the mean value of weight is $73 \pm 12$ and height is $1.67 \pm$ 0.08 .

In the males when compared to normal and overweight subjects, obese group have lesser PEFR value. The difference of mean values PEFR between normal and obese was highly significant $(p=<0.001)$, but the difference between normal and overweight was not significant $(p=>0.005)$. This is because marked degrees of adiposity may be needed to have an effect on pulmonary function. Similar findings were observed in the studies done by Yogesh Saxena Et al. [13], Dayananda. G. [14], K. Sri Ngeswari et, al. [15], Z. M. Ofuya et.al. [16] and Zuhan Gundogdu et.al. [17] although some of these studies have taken slightly lower age group for 
the study compared to the present study.

In male only 2 subjects out of 49 have been underweight so their finding is neglected. In female the difference of mean value of PEFR between normal and overweight and obese was highly significant $(p=<0.001)$. Similar findings were observed by studies done by K. Sri nageswari et.al. [15] and Z. M. Ofuya et.al.[16]. In contract to these studies no such difference of PEFR values between obese and non-obese was seen in studies done by D. V. Muralidhar et.al. [18], and Maciej Sk ${ }^{3}$ adanowSki et al, [19]. In females the difference of mean values of PEFR between normal and underweight was significant $(p=<0.05$ ). this may be due to poor effort. Surprisingly no studies were done on PEFR in underweight adult female to my knowledge.

In the present study in both male and females PEFR is negatively correlated with age, weight, $\mathrm{BMI}$, and positively correlated with height. The correlation of BMI with PEFR was negative and highly significant $(p=<0.001)$, similar finding was observed in studies done by K. Sri nageswari et.al. [15] and Rajesh prajapathi et.al. [20].

Pulmonary function is generally determined by respiratory muscle strength, compliance of the thoracic cavity, airway resistance and elastic recoil of the lungs. It is well known that pulmonary functions may vary according to the physical characteristics including age, height, weight, and altitude [13]. For demonstrating the narrowing of airways, different expiratory flow rates are employed. PEFR is one such parameter that can be easily measured by a peak flow meter and is a convenient tool to measure lung functions in a field study. It is a fairly good indicator of bronchial hyper re sponsiveness, and does not require body temperature pressure saturated (BTPS) correction. The PEFR values are affected by various factors, such as sex, body surface area, obesity, physical activity, posture, environment and racial differences. Obesity has been linked with impaired pulmonary function and airway hyper responsiveness [13].

The association of BMI, with PEFR is primarily restrictive lung function pattern, which could be the result of several mechanisms. Abnormal fat deposition may directly impede the descent of the diaphragm and fat deposition in the chest wall may diminish rib cage movement and thoracic compliance, both leading to restrictive respiration impairment. Other probable mechanism includes the possibility that abdominal fat deposition leads to a redistribution of blood to the thoracic compartment that reduces vital capacity [21].

Reduction in PEF suggests the presence of peripheral air flow limitation increased airway resistance in obese. Additionally, PEF significantly below normal in obese is due to adiposity that may be related to a greater degree of airway narrowing than would be expected on the basis of reduced lung volume alone [21].

This study is a cross-sectional study and precludes definitive casual inference about the relation of $\mathrm{BMI}$ to lung function. Increasing $\mathrm{BMI}$ has opposite effects on PEF. It is important to understand the advantage of weight reduction which significantly slows the decline in lung function. Adiposity variables (FM, FFM) were not directly measured in this study and other factors, particularly the loss of pulmonary elastic tissue are equally important [21].

\section{CONCLUSION}

The mean PEFR values were significantly lower in obese group when compared to normal weight. BMI was significantly and negatively correlated with PEFR in both males and females. The isolated effects of obesity unassociated with other diseases must be identified and the analysis of those effects should be stratified so that obesity related dysfunction may be evaluated in detail. These aspects are extremely important due to currently elevated prevalence of obesity and respiratory disease in our society.

\section{Follow up advice:}

The assessment of lifestyle of the overweight and obese subjects pointed towards a relative lack of physical exercise and greater frequency of consumption of junk food. Such habits contribute towards obesity. The obese subjects were advised about the corrective measure in the form of regular exercise, eating a wellbalanced diet rich in fibre and low in fat and avoiding junk foods to counter ill effects of obesity. 


\section{REFERENCES}

[1]. Frederica Perera. Pollution from Fossil-Fuel Combustion is the Leading Environmental Threat to Global Pediatric Health and Equity: Solutions Exist. Int J Environ Res Public Health. 2018; 15(1): 16.

[2]. Shao-Kun Liu, Shan Cai, Yan Chen, Bing Xiao, Ping Chen, Xu-Dong Xiang. The effect of pollutional haze on pulmonary function. J Thorac Dis. 2016; 8(1): E41-E56.

[3]. Ferror R, Lillioja S, Fontvielle AM, Rising R, Bogardus C, Ravussin E. Lower sedentary metabolic rate in women compared with men. The Journal of Clinical investigation. 1992;90:780-4.

[4]. Lasser S, Bedogni G, Lafortuna CL, Marazzil N, Bustil C, Galli R et al . Relationship between basal metabolic rate, gender, age and body composition in 8,780 white obese subjects. Obesity. 2009;18:71-8.

[5]. Choi JW, Pai SH. Brief communication : Respiratory function is closely associated with basal metabolic rate in elderly persons. Annals of clinical and laboratory science. 2004;34: 99-102.

[6]. Gabridsen AM, Lund MB, Kongerud J, Viken KE, Roislien J, Hjelmesarth J. The relationship between Anthropometric measures, Blood gases and lung function is morbidly obese white subjects. Obes Surg. 2011;21:485-91.

[7]. Tanphaichitr V. Clinical needs and opportunities in assessing body composition. Asia Pacific J Clin Nutr. 1995;4:23-4.

[8]. Joffa Paul Kwaku Price, Nwafor Arthur, Adienbo Ologhaguo Macstephen. Correlation between Body Mass Index and Peak Expiratory Flow Rate of an Indigenous Nigerian Population in the Niger Delta Region. Research Journal of Recent Sciences. 2013;2:28-32.

[9]. Anuradha r. Joshi, Ratan Singh, a. R. Joshi. Correlation of pulmonary function tests with body fat percentage in young individuals. Indian J Physiol Pharmacol. 2008;52:383-8.

[10]. Ebomoyi M.I., Iyawe V.I. Variations of peak expiratory flow rate with anthropometric determinants in a population of healthy adult Nigerians, Nig J. Phy. Sci. 2005;20:85-9.

[11]. Das KK, Dhundasi SA. A study on predictors of Peak Expiratory Flow Rate in Muslim subjects (aged 18 to 20 years) of Karnataka. Indian J Physiol Pharmacol. 2002;46(3):321-7.
[12]. Dhungel KU, Parthasarathy D, Dipali S. Peak expiratory flow rate of Nepalese children and young adults. Kathmandu University Medical Journal. 2008; 6(3):346-54.

[13]. Saxena Y., Purwar B. and Upmanyu R., Adiposity: Determinant of Peak Expiratory Flow Rate in Young Indian Adults Male, Indian J. Chest Dis Allied Sci. 2011;53:29-331.

[14]. Dayananda G. The Effects Of Obesity On Lung Functions. JPBS 2009; 22 (2):17-20.

[15]. Nageswari KS, Sharma R, Kohli DR.Assessment of respiratory and sympathetic cardiovascular parameters in obese school children. Indian J Physiol Pharmacol. 2007;51(3):235-43.

[16]. Ofuya ZM, Georgewill AA, Agu GO. A study of cardiovascular and respiratory parameters in obese and nonobese subjects resident in Port Harcourt. Afr J Appl Zool Environ Biol 2005;7:11-3.

[17]. Gundogdu Z, Eryilmaz N. Correlation between peak flow and body mass index in obese and non-obese children in Kocaeli, Turkey. Prim Care Respir J 2011;20:403-6.

[18]. Muralidhara DV, Bhat Ramesh. Some aspects of pulmonary functions in the underweight and overweight human subjects. Thai Journal of Physiological Sciences. 2007 Mar-Sep;20(1).

[19]. Maciej Sk ${ }^{3}$ adanowSki, Pawe ${ }^{3}$ jaroSz, BarBara Mackiewicz. Variations of Peak Expiratory Flow Rate Associated with Various Factors Among Healthy Adults in a City Setting. Pol J Public Health 2016;126(2):91-4.

[20]. Prajapati R, Dhungel KU, Pramanik T, Ghosh A, Roychowdhury P. Assessment of some pulmonary parameters and cardiorespiratory fitness status in Nepalese medical students. Nepal Med Coll J 2008; 10: $28-29$.

[21]. Kalpojit Saikia, Shrabani Barman. Study of the effect of Body Mass Index (BMI) on Peak Expiratory Flow Rate (PEFR) in Young Healthy Individuals. Global Journal for Research Analysis. 2016;5.

How to cite this article: G. Reen Prasoona, S Sarah Nightigale. STUDY OF CORRELATION BETWEEN BMI AND PEFR RATE IN RAYALASEEMA POPULATION. Int J Intg Med Sci. 2019;6(2):780-784. DOI: 10.16965/ ijims.2019.106 